\title{
Inhibitory action of different doses of tripterygium hypoglaucum hutch on expression of hypoxia inducible factor-1 $\alpha$ in collagen II-induced arthritis rat model
}

\author{
NAIXIANG LUO, SHASHA LI, GUIFENG YUAN, SHUANG LIANG, JING LIU
}

College of Basic Medical Sciences, Guilin Medical University, Guilin, Guangxi 541004, P.R. China

\begin{abstract}
To investigate the inhibitory action of different doses of tripterygium hypoglaucum hutch (THH) on the expression of hypoxia-inducible factor-1 $\alpha(H I F-1 \alpha)$ in collagen II-induced arthritis $(C I A)$ rat model.

Material and methods: CIA rat model was established. Rats were randomly divided into five groups. Rats in the treatment group were received high, moderate or low doses of THH for $30 \mathrm{ds}$, and drugs administered by gastrogavage. Morphological changes of ankle joints and arthritis index (AI) were observed. HIF-1 $\alpha$ expression was examined by RT-PCR and immunohistochemical staining technique.

Results: THH inhibited joint swelling and destruction in CIA, significantly reduced the volume of paw and arthritis index, suppressed HIF-1 $\alpha$ expression and synovial membrane's proliferation in CIA.

Conclusions: The results showed that THH had a good therapeutic effect on CIA rats. The mechanism that HTT treatment RA may correlate with regulation of hypoxia inducible factor-1 $\alpha$ HIF-1 $\alpha$ expression in both peripheral blood and synovial tissue.
\end{abstract}

Key words: tripterygium hypoglaucum hutch, hypoxia inducible factor-1 $\alpha$, collagen II-induced arthritis, rheumatoid arthritis, RA synovial tissue.

(Centr Eur J Immunol 2013; 38 (1): 8-14)

\section{Introduction}

Rheumatoid arthritis (RA) is a chronic, progressive, systemic autoimmune disease. In RA, the basic pathological changes in synovitis similar to tumor growth characteristics [1]. Rheumatoid arthritis caused joint redness, swelling, heat, pain and dysfunction in early stage [2-4], changes and progressive erosion, stiffness, deformity, bone loss, muscle atrophy and high morbidity. Rheumatoid arthritis seriously impacts on the quality of life. Rheumatoid arthritis is not only damaged the joints, but also caused the serious complications and a variety of extra-articular manifestations. Without proper treatment, RA would be delay healing, and even lead to joint deformity in late stage [5].

Over the past century, there were drugs that inhibited the progression of RA, e.g. disease-modifying anti-rheumatic drugs (DMARDs) and biological agents, but the efficacy of the treatment effect is limited [6-8]. Rheumatoid arthritis treatment using the Chinese herbs had evolved over thousands of years of clinical application. The application was limited because the drugs had more or less toxic and side effects $[9,10]$. Tripterygium hypoglaucum hutch (THH) is a traditional Chinese herbal medicine, also known as pink back hook, huobahuagen, smilax, with its active ingredients alkaloids (triptolide type alkali, etc.), diterpene type (epoxy diterpene lactones), triterpenes (triptolide a-level), mainly have the effect of anti-inflammatory, immune and the effect of anti-tumor [11]. Compared with tripterygium, THH takes the advantages of safety and lower toxicity, providing curative effect for the clinical treatment of rheumatoid arthritis, lupus and other autoimmune diseases [12]. Pathological features and immunological characteristics of collagen II-induced arthritis (CIA) rat model are similar to human RA, so the CIA rat model become the best animal model for study of RA. We confirmed that HIF- $1 \alpha$ existed in RA synovial tissue and it is related to the degree of inflammation. It indicates that HIF-1 $\alpha$ plays an important role in RA synovial tissue and angiogenesis $[4,12]$.

Correspondence: Senzhou Chen, Professor of College of Basic Medical Sciences, Guilin Medical University, Guilin, Guangxi 541004, People's Republic of China, tel. +86 773 2887388, fax +86 773 2889218, e-mail: senzhou@163.com 


\section{Material and methods}

\section{Animals}

Sixty healthy Wistar rats (male and female, weighing 150-180 g, animal level: SPF) provided by the Laboratory Animal Center, Guilin Medical University. Animal Experimental Ethical Inspection No: SCXK Gui 2007-0001.

\section{Reagents}

Tripterygium hypoglaucum hutch $(\mathrm{THH})$ was purchased from Chongqing Pharmaceutical Research Institute Co., Ltd. China. Dexamethasone was provided by Shandong Lukang Pharmaceutical Co., Ltd.; Bovine collagen type II was purchased from Chondrex Company, USA. Freund's incomplete adjuvant (IFA) was purchased from Sigma, USA. Concentrated mouse monoclonal anti-HIF- $1 \alpha$ antibody was purchased from Abcam, Inc.UK. Ready-to-use goat anti-mouse secondary antibody was provided by Fuzhou Maixin Bio-engineering Co., Ltd. China. TRIZOL was purchased from Invitrogen Corporation, USA. RT-PCR kit was provided by Dalian Bao Bio-engineering Co., Ltd. China. MARK was provided by Shenggong Bio-engineering Technology Services Co., Ltd. Shanghai, China.

\section{Establishment of rat model}

\section{Animal groupings and labeling}

Ten rats were assigned to the control group without treatment. The remaining 50 rats were randomly divided into five groups of 10 rats each after CIA rat model was established. They were the control, the dexamethasone treated, the THH treated groups (high, moderate and low doses of THH were given, respectively). Animals in each group were numbered at random from 1 to 10 .

\section{Animal vaccination}

Collagen II-induced arthritis (CIA) rat model is established by vaccination [13]. Rats were injected into the roots of the rear and tail with $0.5 \mathrm{ml}$ of the emulsion which was mixed by Collagen II and incomplete Freund's adjuvant, the emulsion elicit immune responses. The same emulsion was injected $14 \mathrm{~d}$ after the primary immunization. Anesthesia was given by intraperitoneal injection of $10 \%$ chloral hydrate $(3-3.5 \mathrm{ml} / \mathrm{kg})$. The rat dorsal root hair was cut, both the heads and tails were fixed after alcohol disinfection. Rats were injected with $0.5 \mathrm{ml}$ of the emulsion. Immediately after the injection, a white lump could be seen on the skin.

\section{Drug treatment}

Drug therapy started $28 \mathrm{~d}$ after the first immunization. The rats in group A (the control) received saline $(0.2 \mathrm{ml} /$ $\mathrm{kg} / \mathrm{d})$. The rats in group B, C, D, E, F were infused with dexamethasone $(0.08 \mathrm{mg} / \mathrm{kg} / \mathrm{d})$, high dose of $\mathrm{THH}$ (400 mg/kg/d), moderate dose of THH (300 mg/kg/d) and low dose of THH $(200 \mathrm{mg} / \mathrm{kg} / \mathrm{d})$, respectively. The rats were administered intragastrically once a day for 30 consecutive days.

\section{Semi-quantitative RT-PCR analysis of hypoxia-inducible factor- $1 \alpha$ expression in peripheral blood}

After treatment, rats were anesthetized and blood was obtained from heart to extract HIF- $1 \alpha$ mRNA for PT-PCR analysis. The total RNA was extracted by Trizol from blood sample of $1 \mathrm{ml}$ that obtained from heart, adding nucleasefree water, stored at $-80^{\circ} \mathrm{C}$. According to the instructions of the two-step RT-PCR kit, first strand synthesis of DNA was obtain from the following step. First is deformation and annealing response: Nuclease-free water was added into dNTP Mixture $1 \mu \mathrm{l}$, oligo Dt Prime $1 \mu \mathrm{l}$ and template RNA $3 \mu \mathrm{l}$ to total volume of $10 \mu \mathrm{l}$, kept at $65^{\circ} \mathrm{C}$ for $5 \mathrm{~min}, 4^{\circ} \mathrm{C}$ and then stored at $-20^{\circ} \mathrm{C}$. $10 \mu \mathrm{l}$ of the same denaturation stock solution after annealing, $5 \times$ PrimeScript $^{\mathrm{TM}}$ buffer $4 \mu \mathrm{l}$, RNase inhibitor $0.5 \mu \mathrm{l}$, PrimeScript ${ }^{\mathrm{TM}}$ Rtase $0.5 \mu \mathrm{l}$ and RNase free $\mathrm{dH}_{2} \mathrm{O} 5 \mu \mathrm{l}$ were taken, kept at $45^{\circ} \mathrm{C}$ for $30 \mathrm{~min}$, $95^{\circ} \mathrm{C}$ for $5 \mathrm{~min}$ and then stored at $-20^{\circ} \mathrm{C}$. Then, PCR reaction system consists of $10 \times$ PCR Buffer $\alpha 5 \mu$, dNTPMixture $2 \mu \mathrm{l}$, upstream primer $0.5 \mu \mathrm{l}$, downstream primer $0.5 \mu \mathrm{l}$ and TaKaRa EX Taq ${ }^{\mathrm{TM}}$ HS $0.5 \mu$ l. GAPDH was selected as an internal control, GAPDH primer sequences were: upstream 5'-TCC CTC AAG ATT GTC AGC AA-3 '; downstream 5'-AGA TCC ACA ACG GAT ACA TT-3; fragment length: $303 \mathrm{bp}$. HIF-1 $\alpha$ primer sequences upstream: 5'-ACA GGA TTC CAG CAG AC-3'; downstream: 5'-TTC CAA GAA AGC GAC AT-3'; fragment length: $461 \mathrm{bp}$. Reaction conditions: $94^{\circ} \mathrm{C} 30 \mathrm{~s}, 50^{\circ} \mathrm{C} 30 \mathrm{~s}$, $72^{\circ} \mathrm{C} 45 \mathrm{~s}, 30$ cycles. Stored at $4^{\circ} \mathrm{C} .5 \mu \mathrm{l}$ of the reaction product was then determined by agarose gel electrophoresis.

\section{Immunohistochemical detection of hypoxia-inducible factor-1 $\alpha$ expression in synovial tissue}

Anti-HIF- $1 \alpha$ antibody as the first antibody. Instead of anti-HIF-1 $\alpha$, phosphate buffered saline (PBS) was used for the negative control. Breast cancer was used as positive control. The immunohistochemical staining was performed according to the instructions of SP kit.

\section{Observation of index}

The general status of rats and weight measurements

Changes of hair color, consciousness, activity status, appetite and joint swelling degrees were observed, body weight of each rat was recorded once a week.

\section{Arthritis index [14]}

Four scores method were using. According to the degree of swelling in rat ankle, metatarsophalangeal joints and numbers of the affected joints. Normal: 0 score, swelling in 1 joint: 1 score, swelling in 2 and more than 2 joints: 
2 scores, swelling severely in ankle joints: 3 scores, ankle joints and feet severely inflamed: 4 scores. All feet severely inflamed including all ankle joints and claws, sometimes the feet couldn't bear the body weight. The limbs were scored, respectively, and the arthritis index (AI) was calculated for each individual rat by assessing the presence and severity of joint inflammation.

\section{Semi quantitative RT-PCR analysis}

Gray scale scanning was performed on electrophoresis strips using an image acquisition and analysis system between the different groups. The ratio between the gray value of HIF- $1 \alpha$ mRNA and GADPH bands) was taken as measuring parameters, HIF-1 $\alpha$ mRNA expression was analyzed.

\section{The synovial pathology score}

The synovial pathology score [15] was using under the HE staining, through following 3 aspects: synovial cell hyperplasis, inflammation and angiogenesis of synovial underlayer. Scores of synovial cell hyperplasia: less than 3 layers: 0 score, 3-4 layers: 1 score, 5-6 layers: 2 scores, more than 6 layers: 3 scores. The degrees of inflammation: no lymphocyte infiltration: 0 score, lymphocytic aggregation: 1 score, diffuse distribution of lymphoid follicles: 2 scores, lymphoid follicles associated with germinal center: 3 scores; Angiogenesis scores: no new blood vessels developed: 0 score, mild angiogenesis: 1 score, moderate: 2 scores, severe: 3 scores. The accumulative summation in the above 3 aspects was the total pathology score.

\section{Assessment and grading the results of immunohistochemical staining}

With reference to the method reported by Birner et al. [16], after the immunohistochemistry staining. Ten fields of each slice were randomly observed $(10 \times 40)$. Score was given in accordance with (1) the positive immunohistochemistry staining grade. Scored 0 for no colour, the same as the background-colour of slice; Pale yellow scored 1, slightly higher than the background-color; Brownish yellow scored 2, obviously higher than the the backgroundcolour and reddish brown scored 3. (2) The percentage of positive cells of immunohistochemistry staining. Scored 0 for negative; Scored 1 for less than 10\%; Scored 2 for $11 \%$ $-50 \%$; Scored 3 for $51 \%-75 \%$ and over $75 \%$, scored 4 . (3) A positive result was determined by multiply of two integrals. HIF- $1 \alpha$ positive cells in both cytoplasm or nucleus dyed brownish yellow or reddish brown.

\section{Statistical analysis}

Data were processed by SPSS16 statistical software. Data on normal distribution were expressed by $\bar{x} \pm s$. Oneway analysis of variance (ANOVA) was applied to test the differences among the groups. $P<0.05$, it was considered to be statistically significant.

\section{Results}

\section{Collagen II-induced arthritis rat model}

In the model group (50 rats), ankle and toe metatarsophalangeal joint swelling was found on 12 days after the first immunization. Swelling was not observed in the normal control group. A significant reduction in joint swelling in all treatment groups after treatment, among them, the effect of dexamethasone is best, but the feet of rats in the model group were still swollen.

\section{Changes of rat arthritis index and the degree of joint swelling}

Rats in the normal control group shows no swelling. Surface redness of the rat toes begin to be seen in the model group rats after 7 days from the first vaccination. Skin temperature is increasing, paw swelling, joint stiffness, activity limitation appeared, and then the swelling of joints begin to reduce. After the treatment, all symptom is remission (Fig. 1). With the development of inflammation, AI increased gradually (Table 1). In the control group, $\mathrm{AI}<1$.

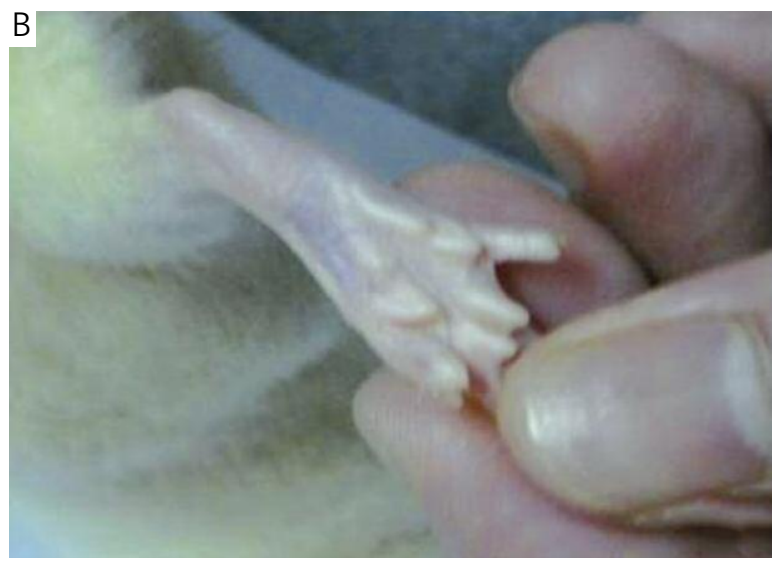

Fig. 1. The swell degree of model group and the treatment group. A) Model of the control group; B) Treatment group 
Table 1. Comparison of the arthritic index (AI) of rats

\begin{tabular}{lcccc}
\hline Group & Case & Day 1 & Day 28 & Last day \\
\hline normal control & 10 & $0.500 \pm 0.707$ & $0.300 \pm 0.483^{\mathrm{b}}$ & $0.400 \pm 0.516^{\mathrm{b}}$ \\
\hline model control & 10 & $0.500 \pm 0.527$ & $9.800 \pm 2.098^{\mathrm{a}}$ & $7.300 \pm 1.337^{\mathrm{a}}$ \\
\hline dexamethasone treatment & 10 & $0.300 \pm 0.483$ & $10.300 \pm 2.584^{\mathrm{a}}$ & $2.700 \pm 0.823^{\mathrm{a}, \mathrm{b}}$ \\
\hline high-dose treatment & 10 & $0.400 \pm 0.516$ & $10.000 \pm 3.464^{\mathrm{a}}$ & $3.500 \pm 1.900^{\mathrm{a}, \mathrm{b}}$ \\
\hline moderate-dose treatment & 10 & $0.200 \pm 0.421$ & $9.400 \pm 2.319^{\mathrm{a}}$ & $3.100 \pm 1.449^{\mathrm{a}, \mathrm{b}}$ \\
\hline low-dose treatment & 10 & $0.400 \pm 0.699$ & $9.600 \pm 2.066^{\mathrm{a}}$ & $3.900 \pm 2.234^{\mathrm{a}, \mathrm{b}}$ \\
\hline
\end{tabular}

${ }^{a}$ compare to the normal control group $(p<0.05)$

$b_{\text {compare to the model control group }(p<0.05)}$
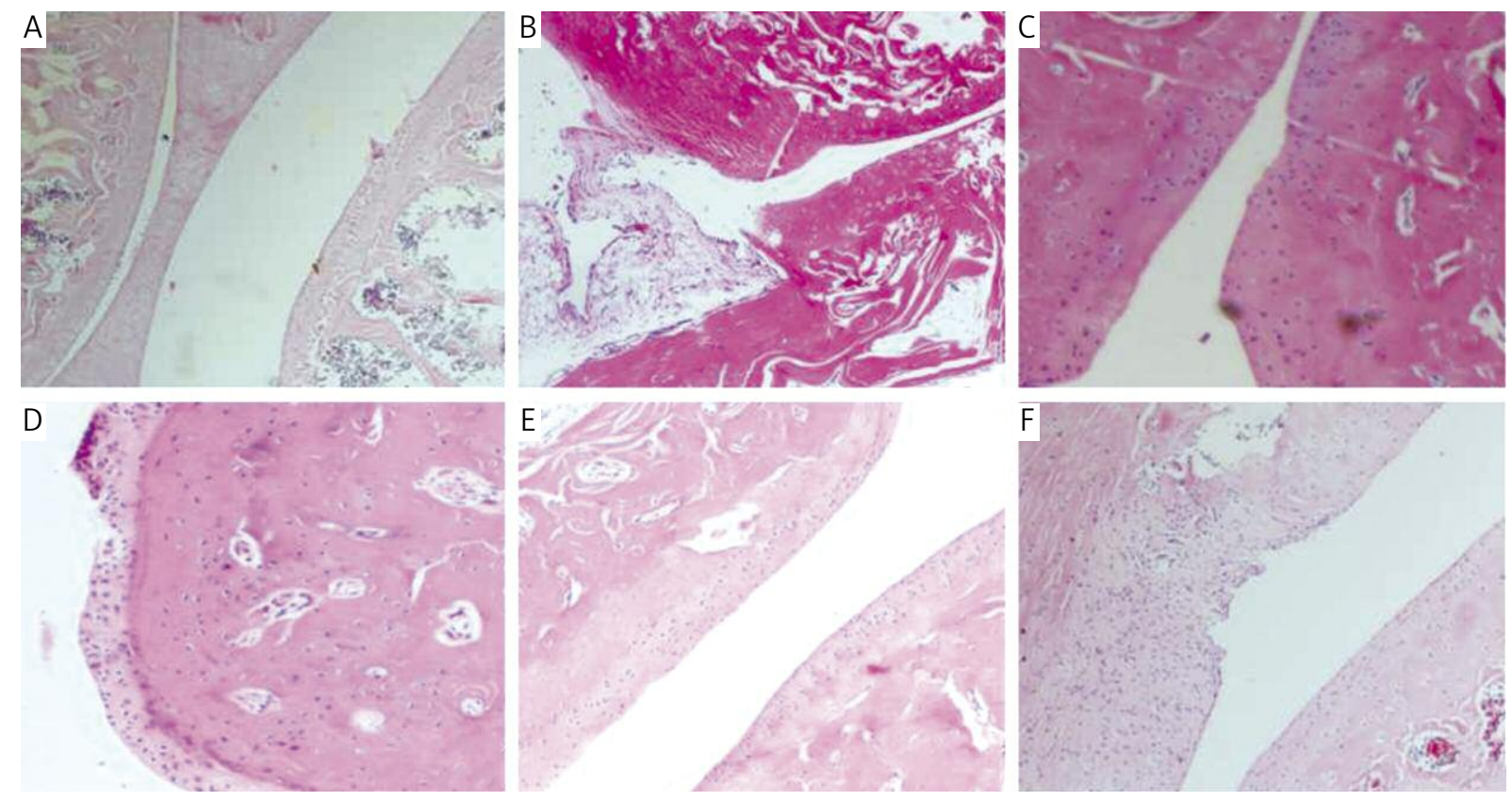

Fig. 2. Histologic analysis of ankle joints on HE staining. A) Normal control group (original magnification 200×); B) Model of the control group (original magnification 200×); C) Treatment group of dexamethasone (original magnification 200×); D) Treatment group of high-dose THH (original magnification 200x); E) Treatment group of moderate-dose THH (original magnification 200×); F) Treatment group of low-dose THH (original magnification 200×)

The AI in the model group reached a peak level in $21 \mathrm{~d}$, and then decreased.

\section{Pathological changes in rat ankle joints}

Normal rat synovium consists of 1 to 2 layers of synovial flat cells, without inflammation and angiogenesis, structural integrity of joints, thick cartilage layers, smooth surface, no structural damage (Fig. 2A).

In the CIA model groups, the synovial cell layers increased to 10-15, synovial hyperplasia led to formation of the pannus, inflammatory cell infiltration. As the synovial hyperplasia, intra-articular synovial cell layers growths like fluff, with a lot of fluff inflammatory cell infiltration. Along with time passing, the cartilage and the surface of hya- line cartilage began to damaged, local fibrosis, joint fibrous tissue adhesions and joint bone was damaged (Fig. 2B).

Dexamethasone had the best therapeutic efficacy in the treatment groups. Normal 2-3 layers of synovial cells were seen in the tissues, almost no inflammatory cell and caused some bone tissue destruction during the model was established (Fig. 2C).

The high dose THH had anti-inflammatory effect. There were very few inflammatory cells, synovial cell layers increased to 5-6 layers, slightly increased comparing with the normal control group, but there was little destruction of bone (Fig. 2D).

The moderate dose THH group had the best therapeutic effect in the three THH treated groups. Layers in normal levels; inflammation and the pannus disappeared (Fig. 2E). 
Table 2. Pathological scores of CIA synovium, $\log (\bar{x} \pm s)$

\begin{tabular}{|c|c|c|c|c|}
\hline Group & Total score & Synovial hyperplasia & Inflammatory cell infiltration & Neovascularization \\
\hline normal control & $0.090 \pm 0.145^{\mathrm{b}}$ & $0.010 \pm 0.001^{b}$ & $0.024 \pm 0.010^{\mathrm{b}}$ & $0.012 \pm 0.003^{b}$ \\
\hline model control & $0.771 \pm 0.081^{\mathrm{a}}$ & $0.477 \pm 0.001^{\mathrm{a}}$ & $0.145 \pm 0.046^{\mathrm{a}}$ & $0.276 \pm 0.162^{\mathrm{a}}$ \\
\hline dexamethasone treatment & $0.474 \pm 0.131^{\mathrm{a}, \mathrm{b}}$ & $0.047 \pm 0.151^{b}$ & $0.086 \pm 0.025^{b}$ & $0.120 \pm 0.155^{b}$ \\
\hline high-dose treatment & $0.635 \pm 0.092^{\mathrm{a}, \mathrm{b}}$ & $0.293 \pm 0.174^{\mathrm{a}, \mathrm{b}}$ & $0.951 \pm 0.030$ & $0.210 \pm 0.145^{\mathrm{a}}$ \\
\hline moderate-dose treatment & $0.574 \pm 0.131^{\mathrm{a}, \mathrm{b}}$ & $0.306 \pm 0.130^{\mathrm{a}, \mathrm{b}}$ & $0.010 \pm 0.004^{b}$ & $0.201 \pm 0.151^{\mathrm{a}}$ \\
\hline low-dose treatment & $0.640 \pm 0.112^{\mathrm{a}, \mathrm{b}}$ & $0.341 \pm 0.148^{\mathrm{a}, \mathrm{b}}$ & $0.050 \pm 0.014^{b}$ & $0.246 \pm 0.168^{a}$ \\
\hline
\end{tabular}

$a_{\text {compare to the normal control group }(p<0.05)}$

$b_{\text {compare to the model control group }(p<0.05)}$

Therapeutic efficacy of the low dose treatment group was not so obvious, a small amount of inflammatory cells existed, and bone and joint tissues were destroyed. This would be because of the insufficient dose (Fig. 2F).

Pathological scores of CIA ankle synovium revealed that there were differences in the joint lesions between the treatment groups and model control group $(p<0.05)$ as well as normal control group $(p<0.05)$ (Table 2$)$.

\section{The expression of hypoxia-inducible factor- $1 \alpha$ in the CIA model rat}

The expression of hypoxia-inducible factor- $1 \alpha$ protein in CIA synovium

The expression of HIF-1 $\alpha$ protein was not found in the normal control group (Fig. 3A).
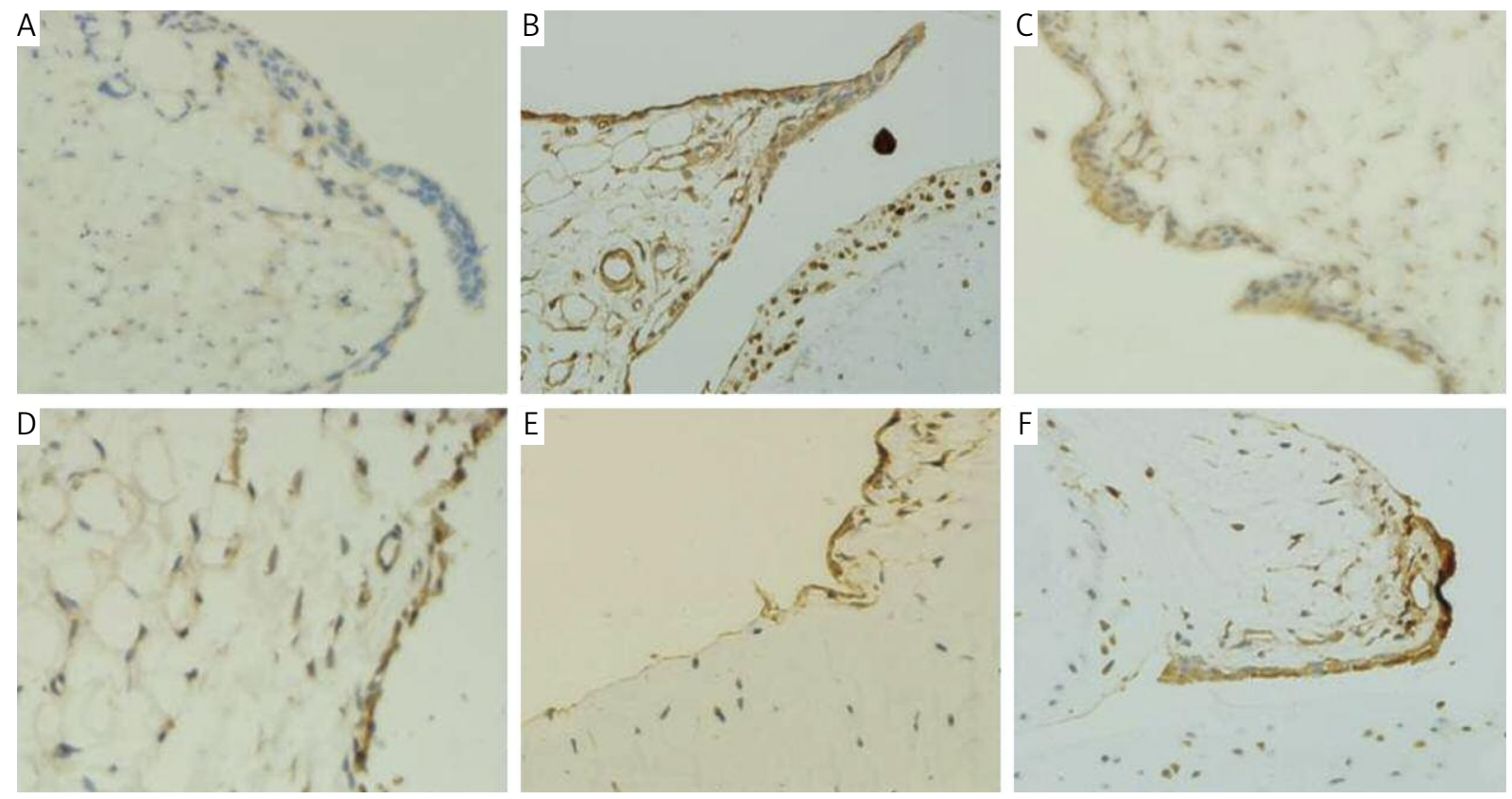

Fig. 3. The immunohistochemical results of HIF-1 $\alpha$ in Rats joint's synovial. A) Normal control group (original magnification 400x); B) Model of the control group (original magnification 400x); C) Treatment group of dexamethasone (original magnification 400×); D) Treatment group of high-dose THH (original magnification 400×); E) Treatment group of moderate-dose THH (original magnification 400×); F) Treatment group of low-dose THH (original magnification 400×) 
Table 3. Immunohistochemical scores of HIF-1 $\alpha$ protein expression in CIA synovium, $\log (\bar{x} \pm s)$

\begin{tabular}{lcc}
\hline Group & Case & HIF-1 $\alpha$ \\
\hline normal control & 10 & $1.300 \pm 0.856^{\mathrm{b}}$ \\
\hline model control & 10 & $7.810 \pm 3.097^{\mathrm{a}}$ \\
\hline dexamethasone treatment & 10 & $2.860 \pm 1.255^{\mathrm{b}}$ \\
\hline high-dose treatment & 10 & $4.653 \pm 2.059^{\mathrm{a}, \mathrm{b}}$ \\
\hline moderate-dose treatment & 10 & $3.775 \pm 1.774^{\mathrm{a}, \mathrm{b}}$ \\
\hline low-dose treatment & 10 & $4.728 \pm 1.741^{\mathrm{a}, \mathrm{b}}$ \\
\hline
\end{tabular}

a compare to the normal control group $(p<0.05)$

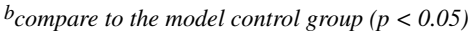

Relatively small amount of HIF-1 $\alpha$ (brown color) was expressed in the nucleus of synovial cells, synovial underlay cells, endothelial cells and fibroblast cells in the low dose treatment group (Fig. 3F).

The above demonstrated that HIF- $1 \alpha$ expression increased in the model group, but significantly decreased in the treated groups. The results of semi-quantitative scoring showed some differences between model and treatment groups in HIF-1 $\alpha$ expression $(p<0.05)$, that it was statistically significant (Table 3).

\section{The expression of hypoxia-inducible factor- $1 \alpha$} mRNA in the peripheral blood of CIA rat

In molecular level, there was no expression of HIF- $1 \alpha$ mRNA in the normal control group, while the high expression of HIF-1 $\alpha$ mRNA was found in the model control group. Low expression of HIF-1 $\alpha$ in the treated groups (Fig. 4).

Semi-quantitative method was used for a statistical analysis, using the date that each group' gray value of the purpose band/ the internal reference band. The results showed that there were significant differences in HIF- $1 \alpha$ expression between THH (high, medium and low-doses), dexamethasone treatment and CIA model, normal control groups $(p<0.05)$ (Table 4).

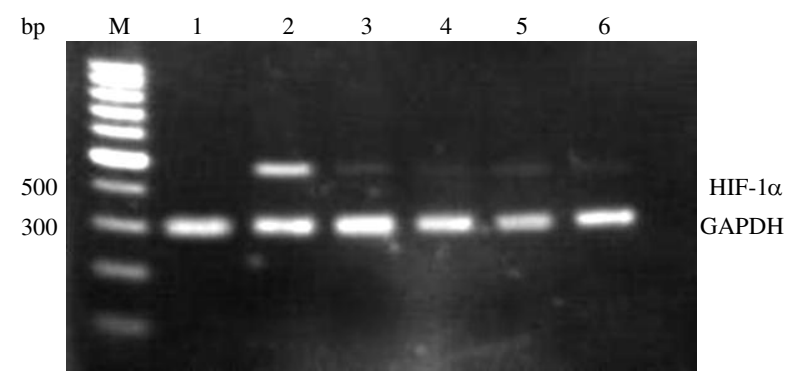

Fig. 4. The results of RT-PCR in each group of rats. The stripe of figure in the following order from left to right: normal control group, model of the control group, treatment group of dexamethasone, treatment group of high-dose $\mathrm{THH}$, treatment group of moderate-dose THH, treatment group of low-dose THH

\section{Discussion}

We can see from the AI value and the results of HE stain, CIA model was successfully established. Symptoms of synovial cell hyperplasia, inflammatory cell infiltration, pannus formation, cartilage and bone destruction occurred in the model rats, all those symptom similar to human with RA. There were significant differences between THH treatment (high, moderate and low-dose) and model control groups $(p<0.05)$.

It is proved that the expression of HIF- $1 \alpha$ is related to both angiogenesis and inflammation in rheumatoid arthritis $[17,18]$. As regulator of angiogenesis in RA, it's up regulation of vascular endothelial growth factor (VEGF) $[19,20]$. Vascular endothelial growth factor become the new therapy target $[21,22]$.

In this study, RT-PCR and immunohistochemistry were using, the differences of the expression in synovial tissue between treatment and model control groups were examined on the level of molecular biology and protein. It demonstrated that THH suppressed the expression of HIF-1 $\alpha$ in the peripheral blood and synovial tissue.

Our research reveals that in CIA model THH inhibits the expression of HIF-1 $\alpha$ both in peripheral blood and synovial tissue. The inhibitory effect of THH on the expression of HIF- $1 \alpha$ leads to further down regulation of VEGF, apoptosis gene expression, inflammatory factor chemotaxis in the peripheral blood and pannus formation in synovial tissue. The effect of THH can increase apoptosis and reduces inflammation [23]. We believe that the effect of THH is correlated with the regulation of HIF-1 $\alpha$ expression in the peripheral blood and synovial tissue. Therefore, it provide a new idea for clinical treatment of RA [24].

We gratefully acknowledge that this project was financially supported by the Natural Science Foundation of Guangxi, P.R. China (No. 0575106) and Research Foundation of Guangxi Education Department (No. 200911MS160).

Table 4. Gray scale of HIF- $1 \alpha$ mRNA expression of peripheral blood in different group

\begin{tabular}{lcc}
\hline Group & Case & HIF-1 $\alpha$ \\
\hline normal control & 10 & $0.090 \pm 0.145^{\mathrm{b}}$ \\
\hline model control & 10 & $0.771 \pm 0.082^{\mathrm{a}}$ \\
\hline dexamethasone treatment & 10 & $0.474 \pm 0.131^{\mathrm{a}, \mathrm{b}}$ \\
\hline high-dose treatment & 10 & $0.635 \pm 0.092^{\mathrm{a}, \mathrm{b}}$ \\
\hline moderate-dose treatment & 10 & $0.574 \pm 0.131^{\mathrm{a}, \mathrm{b}}$ \\
\hline low-dose treatment & 10 & $0.640 \pm 0.112^{\mathrm{a}, \mathrm{b}}$ \\
\hline
\end{tabular}

$a_{\text {compare to the normal control group }(p<0.05)}$

$b_{\text {compare to the model control group }(p<0.05)}$ 


\section{References}

1. Rudolph EH, Woods JM (2005): Chemokine expression and regulation of angiogenesis in rheumatoid arthritis. Curr Pharm Des 11: 613-631.

2. Choi YK, Kim CK, Lee H, et al. (2010): Carbon monoxide promotes VEGF expression by increasing HIF-1alpha protein level via two distinct mechanisms, translational activation and stabilization of HIF-1alpha protein. J. Biol Chem 285: 32116-32125.

3. Sivakumar B, Akhavani MA, Winlove CP, et al. (2008): Synovial hypoxia as a cause of tendon rupture in rheumatoid arthritis. J Hand Surg Am 33: 49-58.

4. Senzhou C, Xianfeng W, Qiaoyan H, et al. (2010): The significance and expression of HIF-1 $\alpha$ in CIA model. Chin J Cell Mol Immunol 30: 115-119.

5. Westra J, Molema G, Kallenberg CG (2010): Hypoxiainducible factor-1 as regulator of angiogenesis in rheumatoid arthritis-therapeutic implications. J Curr Med Chem 17: 54-63.

6. Mittal N, Mittal R, Sharma A, et al. (2012): Treatment failure with disease-modifying antirheumatic drugs in rheumatoid arthritis patients. Singapore Med J 53: 532-536.

7. Chakravarty K, McDonald H, Pullar T, et al. (2008): BSR/BHPR guideline for disease-modifying anti-rheumatic drug (DMARD) therapy in consultation with the British Association of Dermatologists. Rheumatology (Oxford) 47: 924-925.

8. van der Heijden JW, Dijkmans BA, Scheper RJ, Jansen G (2007): Drug Insight: resistance to methotrexate and other disease-modifying antirheumatic drugs - from bench to bedside. Nat Clin Pract Rheumatol 3: 26-34.

9. Cameron M, Gagnier JJ, Chrubasik S (2011): Herbal therapy for treating rheumatoid arthritis. Cochrane Database Syst Rev (2): CD002948.

10. Cameron M, Gagnier JJ, Little CV, et al. (2009): Evidence of effectiveness of herbal medicinal products in the treatment of arthritis. Part 2: Rheumatoid arthritis. Phytother Res 23: 1647-1662.

11. Martin R, McFarland HF, McFarlin DE (1992): Immunological aspects of demyelinating diseases. Annu Rev Immunol 10: 153-187.

12. Bárdos JI, Ashcroft M (2005): Negative and positive regulation of HIF-1: A complex network. Biochim Biophys Acta 1755: 107-120.

13. Yao ZQ, Zhao JX, Li R, Li ZG (2006): Inhibition of cartilage destruction in collagen-induced arthritis by altered CII 263272 peptide: experiment with rats. Zhonghua Yi Xue Za Zhi 86: 3055-3058.

14. Parkinson JF, Mitrovic B, Merrill JE (1997): The role of nitric oxide in multiple sclerosis. J Mol Med (Berl) 75: 174-186.

15. Tsubaki T, Arita N, Kawakami T, et al. (2005): Characterization of histopathology and gene-expression profiles of synovitis in early rheumatoid arthritis using targeted biopsy specimens. Arthritis Res Ther 7: 825-836.

16. Birner P, Schindl M, Obermair A, et al. (2000): Overexpression of hypoxia-inducible factor 1alpha is a marker for an unfavorable prognosis in early-stage invasive cervical cancer. Cancer Res 60: 4693-4696.

17. Konisti S, Kiriakidis S, Paleolog EM (2012): Hypoxia - a key regulator of angiogenesis and inflammation in rheumatoid arthritis. Nat Rev Rheumatol 8: 153-162.

18. Brouwer E, Gouw AS, Posthumus MD, et al. (2009): Hypoxia inducible factor-1-alpha (HIF-1alpha) is related to both angiogenesis and inflammation in rheumatoid arthritis. Clin Exp Rheumatol 27: 945-951.

19. Taylor PC, Sivakumar B (2005): Hypoxia and angiogenesis in rheumatoid arthritis. Curr Opin Rheumatol 17: 293-298.

20. Giatromanolaki A, Sivridis E, Maltezos E, et al. (2003): Upregulated hypoxia inducible factor-1alpha and -2alpha pathway in rheumatoid arthritis and osteoarthritis. Arthritis Res Ther 5: R193-R198

21. Lainer-Carr D, Brahn E (2007): Angiogenesis inhibition as a therapeutic approach for inflammatory synovitis. Nat Clin Pract Rheumatol 3: 434-442.

22. Szekanecz Z, Koch AE (2008): Vascular involvement in rheumatic diseases: 'vascular rheumatology'. Arthritis Res Ther 10: 224.

23. Shyni GL, Ratheesh M, Sindhu G, Helen A (2010): Antiinflammatory and antioxidant effects of Jeevaneeya Rasayana: an ayurvedic polyherbal formulation on acute and chronic models of inflammation. Immunopharmacol Immunotoxicol 32: 569-575.

24. Brouwer E, Gouw AS, Posthumus MD, et al. (2009): Hypoxia inducible factor-1-alpha (HIF-1alpha) is related to both angiogenesis and inflammation in rheumatoid arthritis. Clin Exp Rheumatol 27: 945-951. 